\title{
HUBUNGAN ANTARA PERANAN P3A DENGAN PARTISIPASI PETANI ANGGOTA P3A \\ (BERDASARKAN PERSEPSI PARA PETANI P3A MEKAR SAUYUNAN DI ANCARAN KABUPATEN KUNINGAN, JAWA BARAT)
}

\section{THE RELATIONSHIP BETWEEN THE ROLE OF P3A AND THE PARTICIPATION OF P3A MEMBERS (BASED ON PERCEPTIONS OF P3A MEKAR SAUYUNAN FARMERS IN ANCARAN, KUNINGAN REGENCY, WEST JAVA)}

\author{
Dedi Sufyadi* $^{*}$, Tedi Hartoyo ${ }^{2}$ \\ ${ }^{1,2}$ Fakultas Pertanian, Universitas Siliwangi \\ *E-mail corresponding: dedi_sufyadi@yahoo.co.id
}

\begin{abstract}
ABSTRAK
Penelitian ini melihat bagaimana peran P3A dalam operasionalisasi dan pemeliharaan jaringan irigasi tersier. Utama nya tentang hubungan antara peran $\mathrm{P} 3 \mathrm{~A}$ dengan partisipasi petani $\mathrm{P} 3 \mathrm{~A}$ dalam operasionalisasi pemeliharaan jaringan irigasi tersier, berdasarkan persepsi petani P3A Mekar Sauyunan di Daerah Irigasi (DI) Ancaran Kabupaten Kuningan. Metode penelitian dilakukan melalui survai pada petani P3A Mekar Sauyunan yang merupakan salah satu dari lima P3A dalam GP3A Mitra Cai di DI Ancaran Kabupaten Kuningan. Penentuan lokasi penelitian secara purposive dan pengambilan sampel dilakukan dengan menggunakan simple random sampling. Kesimpulan sementara yang ingin di jawab yaitu, perihal terdapat hubungan antara peran P3A dengan tingkat partisipasi petani dalam OP jaringan irigasi tersier. Dengan kata lain, semakin tinggi peran P3A maka semakin tinggi pula partisipasi petani anggota P3A tersebut dalam kegiatan OP jaringan irigasi tersier. Hasil penelitian menunjukkan : pertama, peran P3A dalam OP jaringan irigasi tersier telah berjalan baik dengan NT sebesar 86,67 persen. Ke dua, partisipasi petani P3A dalam OP jaringan irigasi tersier telah berjalan baik pula dengan NT sebesar 88,08 persen. Ke tiga, ada hubungan antara peran P3A dengan partisipasi petani P3A, menurut persepsi para petani P3A Mekar Sauyunan di DI Ancaran Kabupaten Kuningan. Disarankan, pemerintah untuk senantiasa peduli terhadap kepentingan para petani, agar peran P3A dan partisipasi petani P3A dalam OP jaringan irigasi tersier senantiasa bertumbuh..
\end{abstract}

Kata kunci: Irigasi, Peran P3A, Partisipasi Petani

\begin{abstract}
This research aims at observing role of $P 3 A$ in operating and maintaining tertiary irrigation network, especially the relationship between the role of P3A and participation of farmers in operating and maintaining tertiary irrigation network based on perception of farmer member of P3A Mekar Sauyunan in Irrigation Region (DI) Ancaran Kabupaten Kuningan. The research was conducted through survey method on farmer of P3A Mekar Sauyunan, one of the five P3A members of GP3A Mitra Cai in DI Ancaran Kabupaten Kuningan. The research site was determined purposively, and sample was taken by means of simple random sampling technique. The hypothesis to be answered was whether or not relationship exists between role of $P 3 A$ and level of participation of farmer in operating and maintaining tertiary irrigation network. In other words, the higher the role of $P 3 A$, the higher the participation of farmer of $P 3 A$ in operating and maintaining tertiary irrigation network would be. The research results indicated that: (1)the role of P3A in operating and maintaining tertiary irrigation network was running well with the NT of 86.67 percent; (2) the participation of farmer of P3A in operation and maintaining tertiary irrigation
\end{abstract}




\section{HUBUNGAN ANTARA PERANAN P3A DENGAN PARTISIPASI PETANI ANGGOTA P3A \\ (BERDASARKAN PERSEPSI PARA PETANI P3A MEKAR SAUYUNAN DI ANCARAN \\ KABUPATEN KUNINGAN, JAWA BARAT)}

Dedi Sufyadi, Tedi Hartoyo

network also has been running well with the NT of 88.08 percent; (3) There was relationship between the role of $P 3 A$ and participation of farmer of $P 3 A$ based on the perception of farmers of P3A Mekar Sauyunan in DI Ancaran KabupatenmKuningan. It was recommended that government to always take care of farmer interests in order that the role of $P 3 A$ and participation of farmer of $P 3 A$ in operating and maintaining tertiary irrigation network will always run in better ways.

Keywords: irrigation, role of $P 3 A$, participation of farmer

\section{PENDAHULUAN}

Bahwa, peran Perkumpulan Petani Pemakai Air (P3A) dalam menjalankan eksistensi, tujuan dan fungsinya serta dalam memecahkan masalah operasi dan pemeliharaan jaringan tersier; tampaknya semakin strategis saja. Menurut UndangUndang Nomor 7 tahun 2004 tentang Sumberdaya Air, pasal 41 ayat 3 dikatakan P3A berhak dan bertanggungjawab atas pengembangan jaringan irigasi tersier. Namun di balik itu ada nya partisipasi petani dalam operasionalisasi dan pemeliharaan jaringan irigasi tersier akan jauh lebih strategis lagi bagi pengelolaan dan pengembangan irigasi secara keseluruhan.

Melalui program Participatory Irrigation Sector Proyect (PISP), Kabupaten Kuningan telah menjadi satu daerah yang cukup menonjol soal keirigasiannya (KPCMO Program PISP Kabupaten Kuningan, 2009). Sejak tahun 2006 dalam rangka pengembangan dan pengelolaan system irigasi partisipatif (PPSIP) telah banyak P3A yang eksis dan bertumbuh tersebar diberbagai Daerah Irigasi (DI). Eksistensi P3A itu lah yang diharapkan dapat mendorong terciptanya peningkatan kesejahteraan petani yang sejalan dengan payung hukum yaitu, Perda Jabar nomor 4 Tahun 2008 pasal 3: irigasi untuk petani.

Dalam konteks PISP itu lah, ingin diketahui apakah ada hubungan antara persepsi petani terhadap peran P3A dengan partisipasi petani dalam operasionalisasi dan pemeliharaan jaringan irigasi. Untuk keperluan tersebut penelitian dilakukan pada petani P3A yang ada di wilayah DI Ancaran Kecamatan Sindangagung Kabupaten Kuningan.

Untuk itu permasalahannya dapat diidentifikasikan yaitu pertama, bagaimana peran P3A Mekar Sauyunan dalam operasionalisasi dan pemeliharaan jaringan irigasi tersier ?. Ke dua, bagaimana partisipasi petani P3A Mekar Sauyunan dalam operasionalisasi dan pemeliharaan jaringan irigasi tersier ?.Ke tiga, bagaimana hubungan antara peran P3A Mekar Sauyunan dengan partisipasi petani P3A tersebut dalam operasionalisasi dan pemeliharaan jaringan irigasi tersier? 
Ada pun yang menjadi tujuan penelitian ini yaitu, pertama, untuk mengetahui Peran P3A Mekar Sauyunan dalam operasionalisasi dan pemeliharaan jaringan irigasi tersier. Ke dua, untuk mengetahui partisipasi petani P3A Mekar Sauyunan dalam operasionalisasi dan pemeliharaan jaringan irigasi tersier. Ke tiga, untuk mengetahui hubungan antara peran P3A Mekar Sauyunan dengan partisipasi petani P3A tersebut dalam operasionalisasi dan pemeliharaan jaringan irigasi tersier.

Sedangkan kegunaan penelitian diperuntukkan kepada pertama, pengembangan profesi dan keilmuan, terutama ilmu Pembangunan pertanian. Ke dua, ikhtiar mencari justifikasi bagi kebijakan pengembangan dan pengelolaan irigasi partisipatif, terutama dalam kaitannya dengan upaya peningkatan kesejahteraan masyarakat tani.

Berdasarkan apa yang dipikirkan, maksud dari pada penelitian ini, dapat di pandang sebagai justifikasi bagi penting nya pembangunan pertanian yang mengusung penguatan kelembagaan dan kesejahteraan petani. Berbicara tentang peran P3A dan partisipasi petani dalam OP jaringan irigasi tersier, ibarat membicarakan wadah dan isi. Dalam hal ini tentu nya ada nya partisipasi petani itu lah yang akan menciptakan keberhasilan pembangunan irigasi di negeri ini.
Diyakini partisipasi petani sebagai isi akan meningkatkan peran P3A dalam menjalankan eksistensi, tujuan dan fungsi nya sebagai wadah.

\section{Menurut Pakpahan,A} bahwa, bentuk organisasi berdampak terhadap kinerja produksi, penggunaan input, kesempatan kerja; perolehan hasil dan kelestarian lingkungan. Seberapa jauh organisasi yang di rekayasa di terima masyarakat bergantung pada struktur wewenang, kepentingan individu, keadaan masyarakat; adat dan kebudayaan. Hal ini mengisyaratkkan bahwa organisasi yang mempunyai nilainilai dan norma yang mampu mengatur anggota nya berperilaku selaras dengan lingkungannya akan mencerminkan suatu totalitas kinerja kehidupan sosial yang khas, organisasi-organisasi tradisional pengelola irigasi yang sampai saat ini bertahan (seperti subak di Bali) membuktikan betapa penting nya organisasi dalam suatu pengelolaan air.

Menurut Rahim Darmo dan Letty Fudjaja (2011), fungsi organisasi $\mathrm{P} 3 \mathrm{~A}$ adalah mendorong anggota nya untuk mengatur penggunaan air secara efisien dan efektif. Hal ini dapat dicapai mengingat bahwa organissasi merupakan fitur kehidupan sosial yang terdiri dari jejaring (network), norma (norm); kepercayaan (trust) yang mampu menggerakkan partisipasi anggota 


\section{HUBUNGAN ANTARA PERANAN P3A DENGAN PARTISIPASI PETANI ANGGOTA P3A (BERDASARKAN PERSEPSI PARA PETANI P3A MEKAR SAUYUNAN DI ANCARAN \\ KABUPATEN KUNINGAN, JAWA BARAT)}

Dedi Sufyadi, Tedi Hartoyo

kelompok untuk mencapai tujuan bersama.

\section{Menurut Siti Asmaul Mustanirah} (2001), pembentukan P3A diharapkan dapat meningkatkan kemampuan petani dalam melaksanakan operasi dan pemeliharaan pada gilirannya dapat meningkatkan produksi dan kesejahteraan petani. Begitu juga menurut Rizki Akbar Maulana (2012), P3A diharapkan dapat lebih berperan dalam pengelolaan irigasi untuk mengatasi masalah pemeliharaan tersebut. Peran P3A yang ada sekarang masih terbatas dan belum mengarah kepada peningkatan fungsi dan peran dalam pengembangan dan pengelolaan irigasi.

Conchelos (1985) dalam Ganjar Kurnia (2004), membagi partisipasi menjadi dua jenis, yaitu partisipasi dalam pengertian teknis dan partisipasi dalam pengertian politik. Partisipasi teknis diartikan sebagai taktik untuk mengikutsertakan masyarakat di dalam aktifitas : mendefinisikan masalah, mengumpulkan data, menganalisa data dan mengimplementasikan hasil nya. Secara umum partisipasi ini seringkali diartikan sebagai keikutsertaan masyarakat di dalam setiap tahapan kegiatan pembangunan, mulai dari perencanaan, pelaksanaan, evalluasi dan memanfaatkan hasil. Partisipasi secara politik diartikan sebagai pemberian kekuasaan dan kontrol kepada masyarakat melalui pemberian pilihanpilihan untuk beraksi, berotonomi dan berefleksi terutama melalui pengembangan dan penguatan kelembagaan.

Partisipasi yang dianggap betulbetul partisipasi adalah self mobilisation (mandiri). Pada partisipasi tipe ini, masyarakat berpartisipasi dengan mengambil inisiatif secara bebas (tidak dipengaruhi/ditekan piihak luar) untuk mengubah sistem-sistem atau nilai-nilai yang mereka miliki. Masyarakat mengembangkan kontak dengan lembaga-lembaga lain untuk mengembangkan kapasitas diri nya dan masyarakat memegang kendali atas pemanfaatan sumberdaya yang ada.

Kesimpulan sementara yang diajukan dalam pe3nelitian ini yaitu, terdapat hubungan antara peran P3A dengan tingkat partisipasi petani dalam operasionalisasi dan pemeliharaan jaringan irigasi tersier.

\section{METODE PENELITIAN}

Penelitian ini akan dilaksanakan dengan menggunakan metode survei di Daerah Irigasi (DI) Ancaran Kabupaten Kuningan. Lokasi penelitian ditentukan secara purposif pada salah satu P3A dari empat P3A yang berada di wilayah DI tersebut. Perlu diketahui bahwa, P3A Mekar Saluyu yang terpilih hanya lah 
didasarkan pada kemampuan finansial peneliti semata.

Pengambilan sampel ditentukan dengan cara simpel random sampling pada satuan populasi petani anggota $\mathrm{P} 3 \mathrm{~A}$ Mekar Saluyu sebanyak 296 orang. 33 orang petani sampel yang teranalisis dapat di anggap cukup reprenstatif dan memenuhi syarat ilmiah.

Data yang dikumpulkan terdiri atas data primer dan data sekunder. Data primer diperoleh dari hasil wawancara langsung dengan petani P3A Mekar Saluyu melalui kuesioner yang telah disiapkan terlebih dahulu. Data sekunder diperoleh dari studi kepustakaan, serta instansi yang terkait dengan penelitian ini. Jadi wilayah studi berada di lapangan dan perkantoran.

Variabel penelitian secara garis besar terdiri dari dua variabel yaitu, variabel peranan $\mathrm{P} 3 \mathrm{~A}$ dan variabel partisipasi petani anggota P3A. Peran P3A di sini yaitu keterlibatan P3A dalam kegiatan OP jaringan irigasi tersier. Variabel ini di bangun oleh empat indikator. Selanjutnya indikator-indikator variabel peran P3A tersebut (Harun Al Rasyid, 1995) diklassifikasikan dengan kategori sebagai berikut :

$$
\text { Klasifikasi }=\frac{\text { skor } \max -\text { skor } \min }{\text { jumlah kategori }}
$$

$\begin{array}{ll}\text { sehingga peran P3A dapat } \\ \text { diklassifikasikan } & : \\ \text { Tinggi } \quad= & 13-18 \\ \text { Sedang } \quad=8-12\end{array}$

Rendah $=3-7$

Sedangkan, yang dimaksud dengan partisipasi petani yaitu, partisipasi petani atau keikut sertaan petani anggota P3A dalam kegiatan OP jaringan irigasi tersier. Variabel ini di bangun oleh empat indikator pula.

Peran P3A dan partisipasi petani dalam operasionalisasi dan pemeliharaan jaringan irigasi tersier di analisis dengan menggunakan analisis Nilai Tertimbang (NT), menggunakan rumus sebagai berikut :

$$
\text { NT }=\frac{\text { Skor yang dicapai }}{\text { skor ideal }} \times 100 \%
$$

Skor ideal merupakan skor tertinggi dari variabel dan indikator, berdasarkan item jumlah pertanyaan dalam kuesioner, sedangkan skor yang di capai berasal dari skor variabel dan indikator-indikator nya yang di dapat dari jawaban pertanyaanpertanyaan yang diajukan (Djoni, 1998).

Peran P3A dan partisipasi petani anggota P3A tersebut di dasarkan pada persepsi petani anggota P3A itu sendiri. Analisis dilakukan dengan menggunakan analisis Nilai Tertimbang (NT), menggunakan rumus sebagai berikut :

$$
\mathrm{NT}=\frac{\text { Skor yang dicapai }}{\text { skor ideal }} \times 100 \%
$$

Skor ideal merupakan skor tertinggi dari variabel dan indikator, berdasarkan item jumlah pertanyaan dalam kuesioner, sedangkan skor yang di capai berasal dari skor variabel dan indikator-indikator nya 


\section{HUBUNGAN ANTARA PERANAN P3A DENGAN PARTISIPASI PETANI ANGGOTA P3A \\ (BERDASARKAN PERSEPSI PARA PETANI P3A MEKAR SAUYUNAN DI ANCARAN \\ KABUPATEN KUNINGAN, JAWA BARAT)}

Dedi Sufyadi, Tedi Hartoyo

yang di dapat dari jawaban pertanyaanpertanyaan yang diajukan (Djoni, 1998).

Hipotesis penelitian yang diajukan, di uji oleh uji korelasi rank sperman. Alat uji ini dapat di simak di bawah ini, dengan rumus sebagai berikut:

$$
r_{s}=1-\frac{6 \sum_{i=1}^{N} d_{i}^{2}}{N^{2}-N}:
$$

jika sedikit rank kembar atau tidak ada sama sekali.

Keterangan :

$r_{\mathrm{s}} \quad=$ Korelasi Rank Spearman

$\mathrm{d}_{\mathrm{i}} \quad=$ Perbedaan antara jumlah rank $X$ dan rank $Y$

$\mathrm{N} \quad=$ Jumlah responden

$$
r_{s}=\frac{\Sigma X^{2}+\Sigma Y^{2}-\Sigma d_{i}^{2}}{2 \sqrt{\Sigma X^{2} \cdot \Sigma Y^{2}}}
$$

jika cukup banyak rank kembar

Keterangan:

$\mathrm{r}_{\mathrm{s}} \quad=$ Korelasi Rank Spearman

$\mathrm{T}=$ Faktor Koreksi

$\mathrm{t}=$ Banyak Kembaran data

di = Perbedaan antara rank $\mathrm{x}$ dan $\mathrm{y}$

Untuk sampel besar jika $N>10$, penentuan signifikasi $r_{s}$ diuji dengan :

$$
\mathrm{t}_{\text {hit }}=r_{s} \sqrt{N-2 / 1-\left(r_{s}\right)^{2}}
$$

Untuk hipotesis yang diajukan, maka $t_{\text {hit }}$ dibandingkan dengan $t_{t a b}, d b=N$ - 2.Hipotesis yang diajukan sebagai berikut:

$\mathrm{H}_{\mathrm{o}}: \rho=0$ : Tidak terdapat hubungan antara peran P3A dengan partisipasi petani anggota P3A tersebut dalam kegiatan OP jaringan irigasi tersier.

$\mathrm{H}_{1}: \rho \neq 0$ : Terdapat hubungan antara peran P3A dengan partisipasi petani anggota $\mathrm{P} 3 \mathrm{~A}$ tersebut dalam kegiatan $\mathrm{OP}$ jaringan irigasi tersier.

Kriteria uji yang digunakan untuk menetapkan keputusan hipotesis tersebut adalah:

Terima $\mathrm{H}_{\mathrm{o}}$ atau tolak $\mathrm{H}_{1}$, jika $\mathrm{t}_{\text {hit }}<\mathrm{t}_{\text {tab }}$

Tolak $\mathrm{H}_{\circ}$ atau terima $\mathrm{H}_{1}$, jika $\mathrm{t}_{\text {hit }} \geq \mathrm{t}_{\text {tab. }}$.

Penelitian ini dilakukan di P3A Mekar Sauyunan Daerah Irigasi Ancaran Kabupaten Kuningan. Ada pun waktu penelitian di bagi menjadi beberapa tahapan sebagai berikut :

1) Tahap persiapan yaitu penyusunan usulan penelitian dilaksanakan pada bulan Mei 2013.

2) Tahap pengumpulan Data di lapangan pada bulan Agustus 2013..

3) Tahap pengolahan data dan penulisan hasil penelitian dilaksanakan pada bulan November 2013 sampai dengan selesai.

\section{HASIL DAN PEMBAHASAN}

\section{Karakteristik Sampel}

Bahwa sebagian besar umur petani tergolong pada umur produktif (15 - 64 tahun). Produktif nya para petani P3A Mekar Sauyunan diharapkan jaringan irigasi tersier dapat senantiasa terpelihara. Begitu juga seluruh petani sampel di P3A Mekar Sauyunan 
berpendidikan rendah/hanya tammat Sekolah Dasar. Di sini dapat lah dikatakan bahwa, sumberdaya manusia di sana masih tergolong rendah, sehingga merupakan kelemahan tersendiri dalam upaya peningkatan inovasi dan teknologi di bidang keirigasian.

Perihal penguasaan lahan, sebagian besar petani anggota P3A Mekar Sauyunan mempunyai lahan < 0,55 ha yaitu sebanyak 21 orang $(63,64$ persen), kepemilikan lahan antara 0,56 $0,76 \mathrm{Ha}$ sebanyak 12 orang $(36,36$ persen). Sementara rata-rata luas kepemilikan lahan usahatani petani P3A Mekar Sauyunan sebesar $0,41 \mathrm{Ha}$. Hal ini menunjukkan bahwa rata-rata kepemilikan lahan petani responden adalah sempit. Soekartawi (2005) menyatakan bahwa, kepemilikan lahan < 0,5 hektar termasuk kategori sempit.

Tentang pengalaman usahatani, sebagian besar petani responden mempunyai pengalaman antara $30-41$ tahun $(63,64$ persen), dengan rata-rata pengalaman petani dalam berusaha tani yaitu 28,58 tahun. Cukup lama nya pengalaman berusahatani para petani P3A, tentu nya memiliki dampak terhadap pengelolaan usahatani dan pemeliharaan jaringan tersier.

Tentang tanggungan keluarga, sebagian besar responden mempunyai tanggungan keluarga antara $2-3$ orang, sebesar 57,58 persen. Hal ini dapat dikatakan, sebagian besar petani responden di P3A Mekar Sauyunan berkeluarga kecil. Keluarga kecil lebih memberikan harapan yang lebih baik bagi terwujud nya pemeliharaan jaringan irigasi tersier.

Persepsi Petani P3A Terhadap Peran P3A dalam Operasi Pemeliharaan Jaringan Irigasi Tersier

Hasil penelitian menunjukkan bahwa, secara keseluruhan peran $\mathrm{P} 3 \mathrm{~A}$ dalam skor operasi dan pemeliharaan jaringan irigasi tersier berkategori tinggi dengan nilai skor 52 dan nilai tertimbang 86,67 . Hal ini berarti bahwa, secara umum peran $\mathrm{P} 3 \mathrm{~A}$ dirasakan sangat penting.

Eksistensi P3A yang ada saat ini berada pada kategori baik dengan skor rata-rata yang diperoleh sebesar 20,15 dari skor ideal 21 dengan nilai tertimbang sebesar 95,95 persen. Hal ini berarti bahwa persepsi para petani P3A terhadap eksistensi P3A yang ada saat ini dapat dikatakan baik. Baik dalam arti P3A itu sudah dapat dirasakan manfaat nya dalamm memenuhi kebutuhan air, pengurus nya sudah diakui; dan memiliki badan hukumm. Memang menurut Hari Prasetijo (2011) bahwa, Himpunan Petani Pemakai Air (HIPPA) atau P3A harus berbentuk badan hukum, pemerintah sebagai fasiilitator, motivator, mengadakan kerjasama pengelolaan, 


\section{HUBUNGAN ANTARA PERANAN P3A DENGAN PARTISIPASI PETANI ANGGOTA P3A \\ (BERDASARKAN PERSEPSI PARA PETANI P3A MEKAR SAUYUNAN DI ANCARAN \\ KABUPATEN KUNINGAN, JAWA BARAT)}

Dedi Sufyadi, Tedi Hartoyo

menyediakan tenaga pendamping, menyediakan sarana produksi, dan memmfasilitasi pembentukan koperasi serba usaha.

Tujuan P3A berada pada kategori baik juga dengan skor rata-rata yang diperoleh sebesar 10,97 dari sor ideal 12 dengan nilai tertimbang sebesar 91,42 persen. Ini mengandung arti bahwa, persepsi para petani P3A terhadap tujuan P3A dapat dikatakan baik. Baik dalam arti tujuan P3A itu sudah sesuai dengan AD/ART, sudah dimengerti dan sudah sesuai dengan keinginan para petani.

Pemecahan masalah yang dilakukan P3A berada pada kategori baik dengan skor rata-rata yang diperoleh sebesar 12,27 dari skor ideal 15 dengan nilai tertimbang sebesar 81,80 persen. Hal ini berarti bahwa, persepsi para petani P3A terhadap inwal pemecahan masalah yang dilakukan P3A ternyata di pandang baik. Baik dalam arti layanan P3A sudah dirasakan ada hasil nya seperti debit air relatif tinggi dan sistem giliran sudah relatif optimal.

Fungsi P3A berada pada kategori baik juga dengan skor rata-rata yang diperoleh sebesar 8,61 dari skor ideal 12 dengan nilai tertimbang sebesar 71,75 persen. Hal ini berarti bahwa, persepsi para petani P3A terhadap fungsi P3A dapar dikatakan baik. Baik dalam arti P3A telah aktif menjalankan fungsi nya seperti, dalam mengumpulkan iuran P3A dan melindungi kebutuhan air irigasi anggota nya.

Dari ke empat indikator yang berkaitan dengan peran P3A dalam operasi dan pemeliharaan jaringan irigasi tersier di atas, dapat lah diindikasikan bahwa,peran P3A dalam operasi dan pemeliharaan jaringan irigasi tersier itu baik. Dengan kata lain, secara konsepsional maupun operasional, peran P3A dalam operasi dan pemeliharaan jaringan irigasi tersier di P3A Mekar Sauyunan itu sudah baik, walau pun memang keberfungsiannya masih harus ditingkatkan.

\section{Partisipasi Petani P3A dalam Operasi dan Pemeliharaan Jaringan Tersier}

Partisipasi petani P3A dalam operasi dan pemeliharaan jaringan irigasi tersier secara keseluruhan berdasarkan hasil penelitian berada pada kategori tinggi dengan nilai skor 42,28 dari nilai ideal 48 dengan nilai tertimbang sebesar 88,08 persen. Hal ini mengandung arti bahwa tingkat partisipasi petani P3A Mekar Sauyunan telah ikut serta dalam mengoperasikan 'dan memelihara jaringan irigasi tersier. Namun dikatakan oleh Ida Dewi Yuliawati (1997) bahwa, pengalaman usahatani dan status penggarapan lahan berpengaruh negatif terhadap tingkat partisipasi petani dalam pengelolaan jaringan irigasi, sedangkan 
jarak lahan terhadap pusat bendungan air dan umur petani berpengaruh positif.

Rapat anggota berada pada kategori tinggi dengan skor rata-rata yang diperoleh sebesar 10,73 dari skor ideal sebesar 12 dengan nilai tertimbang sebesar 89,42 persen. Hal ini berarti bahwa partisipasi petani P3A dalam rapat anggota sebesar 89,42 persen. Dalam satu musim terakhir rapat anggota diikuti oleh petani P3A rata-rata sebanyak dua kali. Partisipasi petani P3A dalammengikuti rapat anggota ini di ukur di samping dengan melihat intensitas keikutsertaan juga di lihat dari segi pengetahuan tentang tugas, fungsi dan wewenanng rapat itu sendiri, banyak nya gagasan/saran/ ide dalam satu kali kegiatan rapat anggota; dan tingkat penerimaan dari forum terhadap saran/gagasan/ide tersebut.

Rencana kerja berada pada kategori tinggi dengan skor rata-ratayang diperoleh sebesar 9,61 dari skor ideal sebesar 12 dengan nilai tertimbang sebesar 80,08 persen. Hal ini berarti bahwa partisipasi petani P3A dalam menyusun rencana kerja sebesar 80,08 persen. Dalam satu musim terakhir membuat rencana kerja diikuti oleh petani P3A rata-rata sebanyak satu kali. Partisipasi petani P3A dalam menyusun rencana kerja ini di ukur juga melalui tingkat pengetahuan akan manfaat rencana kerja dalam $\mathrm{P} 3 \mathrm{~A}$, banyak nya gagasan/ide/saran yang dikemukakan dalam satu kali pembuatan rencana kerja; dan tingkat penerimaan dari forum terhadap saran/gagasan/ide tersebut.

Memelihara jaringan berada pada kategori tinggi dengan skor rata-rata yang diperoleh sebesar 11,82 dari skor ideal sebesar 12 dengan nilai tertimbang sebesar 98,50 persen. Hal ini berarti bahwa, partisipasi petani P3A dalam memelihara jaringan tersier sebesar 98,50 persen. Dalam satu musim terakhir memelihara jaringan tersier diikuti oleh petani P3A rata-rata sebanyak dua kali. Partisipasi petani P3A dalam memelihara jaringan irigasi tersier ini di ukur juga melaluitingkat pengetahuan akan manfaat pemeliharaan jaringan irigasi itu dalam $\mathrm{P} 3 \mathrm{~A}$, tingkat pengetahuan akan kegiatan gotong royong dalam rangka pemeliharaan jaringan irigasi yang dilaksanakan oleh P3A.

Membayar iuran berada pada kategori tinggi dengan skor rata-rata yang diperoleh sebesar 10,12 dari skor ideal sebesar 12 dengan nilai tertimbang sebesar 84,33 persen. Hal ini berarti bahwa, partisipasi petani P3A dalam membayar iuran sebesar 84,33 persen. Partisipasi petani P3A dalam membayar iuran ini di ukur melalui tingkat sumber dana bagi pemeliharaan jaringan irigasi tersier, tingkat kesukaan membayar iuran pokok; tingkat kesukaan membayar iuran khusus; tingkat teguran dari pengurus 


\section{HUBUNGAN ANTARA PERANAN P3A DENGAN PARTISIPASI PETANI ANGGOTA P3A \\ (BERDASARKAN PERSEPSI PARA PETANI P3A MEKAR SAUYUNAN DI ANCARAN \\ KABUPATEN KUNINGAN, JAWA BARAT)}

Dedi Sufyadi, Tedi Hartoyo

P3A akibat keterlambatan dalam membayar iuran. Perlu diketahui menurut Rahim Darmo dan Letty Fudjaja (2011) bahwa, faktor-faktor yang menyebabkan petani tidak membayar IPAIR adalah karena gagal panen, akibat kekurangan air, pengurus yang kurang aktif, tempat tinggal pengurus yang tidak beradapadahamparan pemukiman yag sama dengan anggota. Memang menurut Helmi (2011) pun, penyerahan urusan pemungutan dan pengelolaan dana IPAIR yang otonom dapat mendorong partisipasi pettani dalam membayar iuran.

Hubungan antara Persepsi petani P3A terhadap Peran P3A dengan Partisipasi Petani P3A dalam Operasi dan Pemeliharaan Jaringan Irigasi Tersier

Melalui perhitungan yang di bantu oleh program SPSS, hubungan antara persepsi petani P3A terhadap peran P3A dengan partisipasi petani P3A dalam opetrasi dan pemeliharaan jaringan irigasi tersier dapat dimunculkan. Nilai-nilai pada program SPSS menunjukkan bahwa, nilai degree of freedom (df) adalah 0,01. Nilai koefisien korelasi Rank Spearman (rs) sebesar 0,543. Hal ini dapat diartikan bahwa, besar nya hubungan antara persepsi petani P3A terhadap peran P3A dengan partisipasi petani P3A dalam operasi dan pemeliharaan jaringan irigasi tersier sebesar 54,30 persen.
Hasil uji hipotesis menunjukkan bahwa, terdapat hubungan yang sangat nyata antara persepsi petani P3A terhadap peran $\mathrm{P} 3 \mathrm{~A}$ dengan tingkat partisipasi petani P3A, pada level 0,01. Dengan demikian dapat disimpulkan menolak Ho dan menerima $\mathrm{Hi}$. Hal ini sejalan dengan pendapat masyarakat bahwa, jika lembaga itu baik dalam arti pengurus nya menjalankan tugas dengan benar, maka partisipasi mayarakat mudah terangkat.

Dikatakan oleh Soekanto (2009) bahwa, peranan merupakan proses dinamis kedudukan (status). Apabila seseorang melaksanakan hak dan kewajibannya sesuai dengan kedudukannya, dia menjalankan suatu peranan. Dalam hal ini dapat ditambahkan bahwa, kunci sukses organisasi sangat tergantung dari ada nya dinamika sumberdaya manusia. Oleh kaarena itu lah dinamika peran organisasi akan sejalan dengan dinamika partisipasi anggota organisasi tersebut.

\section{KESIMPULAN}

Berdasarkan pembahasan dapat disimpulkan pertama, menurut persepsi petani P3A dalam operasi dan pemeliharaan jaringan irigasi terssier berada pada kategori baik dengan nilai tertimbang sebesar 86,67 persen. Dengan kata lain, P3A Mekar Sauyunan telah memperlihatkan eksistennsi nya, melaksanakan tujuan organisasi, 
berfungsi dan dapat memecahkan permasalahan dengan baik.Ke dua, partisipasi petani P3A dalam operasi dan pemeliharaan jaringan irigasi tersier berada pada kategori baik dengan nilai tertimbang sebesar 88,08 persen. Dengan kata lain petani P3A Mekar Sauyunan telah berpartisipasi aktif mengikuti rapat anggota, menyusun rencana kerja; turut memelihara jaringan irigasi tersier; dan membayar iuran dengan baik. Ke tiga, terdapat hubungan antara peran $\mathrm{P} 3 \mathrm{a}$ dengan tingkat partisipasi petani P3A dalam opersionalisasi dan pemeliharaan jaringan irigasi tersier. Dengan kata lain dinamika peran organisasi sejalan dengan dinamika partisipasi anggota organisasi tersebut. Berdasarkan kesimpulan dapat disarankan bahwa, pemerintah diharapkan senantiasa peduli terhadap kepentingan para petani, agar peran P3A dan partisipasi petani P3A dalam operasi dan pemeliharaan jaringan irigasi tersier senantiasa bertumbuh.

\section{DAFTAR PUSTAKA}

Agus Pakpahan.1991. Kerangka Analitik untuk Penelitian Rekayasa Sosial : Perspektif Ekonomi Institusi. Prosiding Evaluasi Kelembagaan, Pedesaan. Pusat Penelitian Sosial Ekonomi Pertanian. Bogor.

Djoni. 1998. Hubungan Interpersonal, Kelompok, dan Lingkungan serta Pengaruhnya terhadap Keefektifan Kelompok. Studi Mengenai
Usahatani Terpadu di Kalangan Kelompok Tani di Jawa Barat Bagian Timur. Disertasi. Universitas Padjadjaran. Bandung.

Ganjar Kurnia. 2004. Petani, Pejuang Yang Terpinggirkan. Depdiknas. UNPAD Bandung.

Hari Prasetijo.2011. Studi Pemberdayaan Lembaga Pengelola Jaringan Irigasi di Tingkat Desa. Fak. Teknik Univ Brawijaya. Malang.

Harun Al Rasyid. 1991. Teknik Sampling dan Teknik Penyusunan Skala. Departemen Pendidikan dan Kebudayaan. Kopertis Wilayah IV. Bandung.

Helmi. 2001. Peranan Lembaga P3A/Kejruenblang Dalam Konteks Otonomi Daerah Tentang Air Irigasi di Provinsi Aceh. Jurusan Agroteknologi Fakultas Pertanian Unsyiah. Banda Aceh.

Ida Dewi Yuliawati. 1997. Analisis Faktorfaktor yang Di duga Mempengaruhi Tingkat Partisipasi Petani dalam Pengelolaan Jaringan Irigasi di Tingkat Tersier (Study Kasus Desa Mandopo, Kecamatan Dawuan, Kabupaten Majalengka. Jurusan Sosial. Fakultas Pertanian. IPB.

KPCMO Program PISP Kab. Kuningan. 2009. Laporan Kegiatan Participatory Irrigation Sector Project (PISP).

Perda Jabar nomor 4 Tahun 2008. Tentang Irigasi.

Rahim Darma dan Letty Fudjaja. 2011. Penguatan P3A untuk Pengelolaan IPAIR dan Pemeliharaan Saluran Irigasi di Kabupaten Pinrang. Jurnal Agrisistem - Vol 7 No 1. ISSN. 20890036. 


\section{HUBUNGAN ANTARA PERANAN P3A DENGAN PARTISIPASI PETANI ANGGOTA P3A (BERDASARKAN PERSEPSI PARA PETANI P3A MEKAR SAUYUNAN DI ANCARAN \\ KABUPATEN KUNINGAN, JAWA BARAT) \\ Dedi Sufyadi, Tedi Hartoyo}

Rizki Akbar Maulana. 2012. Operasi dan

Pemeliharaan Irigasi Partisipatif di Cihea.Rizki_AkbarM@com

Siti Asmaul Mustanirah. 2001. Evaluasi Aspek Kelembagaan Pengelolaan Jaringan Irigasi di Tingkat Petani Pada Usahatani Padi Sawah di Kabupaten Banjarbaru Kalimantan Selatan. Jurnal Teknologi Pertanian. Vol 2, no 2, Agustus 2001.
Soekartawi. 2005. Prinsip Dasar Komunikasi Pertanian. Jakarta. UI Press.

Soekanto,S. 2009. Sosiologi Suatu Pengantar. Edisi Baru. Rajawali Press. Jakarta.

Undang-Undang nomor 7 Tahun 2004. Tentang Sumberdaya Air. 